\title{
BREVES CONSIDERAÇÓES SOBRE OS ACORDOS AMBIENTAIS COMO INSTRUMENTO DE PROTEÇÃO DO AMBIENTE
}

\author{
BRIEF CONSIDERATIONS ON ENVIRONMENTAL AGREEMENTS AS AN INSTRUMENT OF \\ ENVIRONMENTAL PROTECTION
}

\author{
Carolina Rodrigues de Freitas \\ Mestre em Direito Civil pela Universidade de Coimbra - Portugal. \\ Advogada \\ carolinarodfreitas@gmail.com
}

\section{RESUMO}

Este trabalho trata do surgimento e aplicação dos acordos voluntários ambientais, especialmente em sua utilização no ordenamento Brasileiro, através do compromisso de ajustamento de conduta. Inicialmente é abordada a ideia conceitual, caracterização e necessidade do instrumento de co-regulação em prol da proteção do ambiente sob o âmbito da comunidade europeia e na legislação brasileira. Na sequência, procura-se destacar a contribuição da adoção de instrumentos alternativos na promoção do princípio do acesso à Justiça e maior eficiência na tutela jurisdicional. Por fim, analisa os novos mecanismos na solução dos conflitos ambientais, que devem ser sustentados na participação do cidadão, em prol do fortalecimento da democracia. Neste ensejo, propóe uma reflexão sobre a implementação e efetividade dos acordos em busca de prevenção e reparação dos danos ambientais.

Palavras-chave: Acordos ambientais. Compromisso de ajustamento de conduta. Acesso à justiça. Efetividade. Proteção do ambiente. 


\begin{abstract}
This paper deals with the emergence and application of the voluntary environmental agreements, focusing on their use in the Brazilian legal order, through a commitment to conduct adjustment. Initially the paper works with the conceptual idea, characterization and necessity of the instrument of co-regulation in favor of the protection of the environment under the European Community and the Brazilian Legislation. Then, it seeks to highlight the contribution of the adoption of alternative instruments in promoting the principle of access to justice and greater efficiency in judicial protection. Finally, it analyzes the new mechanisms in the solution of the environmental conflicts that aim the citizen participation, the strengthening of democracy and the stimulus to social pacification, leading to a reflection on the implementation and effectiveness of the agreements in search of prevention and reparation of environmental damages.
\end{abstract}

Key words: Voluntary environmental agreements. Commitment of conduct adjustment. Access to justice. Effectiveness. Environmental protection.

Data de submissão: 16/03/2018

Data de aceitação: 07/02/2019

\title{
SUMÁRIO
}

INTRODUÇÃO 1. OS ACORDOS VOLUNTÁRIOS AMBIENTAIS NA UNIÃO EUROPÉIA 2. ACORDOS AMBIENTAIS NA LEGISLAÇÃO BRASILEIRA: COMPROMISSO DE AJUSTAMENTO DE CONDUTA. 3. A QUESTIONÁVEL EFETIVIDADE DA REGULAMENTAÇÃO AMBIENTAL NO ORDENAMENTO BRASILEIRO: ACESSO À JUSTIÇA E PARTICIPAÇÁO DEMOCRÁTICA. CONSIDERAÇÕES FINAIS 


\section{INTRODUÇÁO}

Nas ultimas décadas, houve uma tomada de consciência, por parte da população, dos riscos associados aos problemas globais do ambiente e da irreversibilidade dos bens naturais. Logo tornou-se inevitável um desenvolvimento do conhecimento ecológico, a modelação de instrumentos de ação, a reformulação de metodologias de trabalho, o investimento e a criaçấo de tecnologias voltadas ao equilíbrio do uso da natureza pelo homem ${ }^{1}$.

A sociedade pós-industrial conheceu nova modalidade de riscos: os riscos abstratos, que se distinguem por serem globais, imprevisíveis, transfronteiriços, transtemporais, e que podem assumir proporçôes de grande magnitude. A partir disso, urge mensurar os limites da atuação humana em prol da permanência da vida na Terra, pois, sendo o homem responsável pelo seu futuro ${ }^{2}$, deve procurar um nível elevado de proteção ambiental ao menor custo, tanto financeiro como temporal.

Diante de um fraco desempenho das técnicas tradicionais de command and contro ${ }^{\beta}$, tentase encontrar nos sistemas de gestão ambiental uma forma de oxigenar a política ambiental, com base em quatro linhas de força: participação, voluntariedade, complementariedade e prevençãó $0^{4}$.

\footnotetext{
1 Neste sentido e tratando especificamente do direito do tratamento dos resíduos, Aragáo, Maria Alexandra De Sousa. O Princípio do nível elevado de proteçáo e a renovaçáo ecológica do direito do ambiente e dos resíduos. Coimbra: Editora Almedina, 2006.

2 A ampliaçáo do campo de atençáo pelo direito em virtude da maior sensibilidade às consequências ambientais da ação humana e às dinâmicas que a condicionam, conduz ao desenvolvimento da prudência como virtude humana, refletida no quadro de sua liberdade. Logo, consagra-se que a proteçáo ambiental é de responsabilidade de todos, cidadáos e Estado, tanto perante a presente (justiça intrageracional) como para as futuras gerações (justiça intergeracional). Neste sentido, a figura do Sujeito Geração, em CANOTILHO, José Joaquim Gomes. O direito ao ambiente como direito subjectivo, in A tutela jurídica do meio ambiente: presente e futuro, publicado no Boletim da Faculdade de Direito da Universidade de Coimbra, Studia Juridica, no 81,2005 , pag. 47.

$3 \quad$ BLACK, J. Critical Reflections on Regulation, 2002.

4 Conforme Carla Amado Gomes e Eduardo Figueiredo Dias, a participação acontece numa tripla vertente: público em geral, operadores econômicos e trabalhadores de empresa ou organizaçáo; o sistema é de adesão voluntária, deixando às empresas/organizaçóes a decisão de implementar a avaliação do seu desempenho ambiental e o momento de o fazer, convertendo-os em poluidores-colaboradores. Os sistemas de gestão ambiental são complementares ao regime de command and control, pois o setor privado é estimulado a incrementar o desempenho ambiental e sua implementação, ao apontar para índices de proteção superiores aos mínimos exigíveis, tem uma importante componente preventiva e formativa, na medida em que reduz as hipóteses de ocorrência de danos ambientais e ecológicos resultantes da atividade das empresas (GOMES, Carla Amado; DIAS, José Eduardo Figueiredo. Notas reflexivas sobre sistemas de gestão ambiental. In: Revista do Centro de Estudos de Direito do Ordenamento, do Urbanismo e do Ambiente. No 31, Ano XVI, 1.2013, p. 15-16).
} 
A dimensão e gravidades dos problemas ambientais convenceram políticos e industriais de que seria urgente o aparecimento de novos instrumentos ${ }^{5}$ de política ambiental baseados na cooperação. Com isso, abriu-se espaço para a co-regulação 6 .

Foi neste contexto que surgiram os Acordos Voluntários Ambientais ${ }^{7}$, baseado na cooperação para assegurar a prevenção e a reparação de danos ao ambiente. Esta nomenclatura segue o termo utilizado pela Uniáo Europeia, qual seja voluntary environmental agreements. ${ }^{8}$ Já no Brasil é conhecido por compromisso de ajustamento de conduta?

Diante da morosidade e da grande demanda submetida ao Poder Judiciário, as alternativas extrajudiciais se destacam como solução para a resoluçâo dos conflitos. Além disso, a complexidade do conhecimento ambiental requer um saber transdisciplinar e interdisciplinar nas situaçóes concretas de dano iminente ou consumado em que o responsável deve reparar a lesão. Logo, é preciso um instrumento eficaz, com atuação de experts e cuja atuação seja o mais célere possível.

\footnotetext{
5 Outro instrumento regulatório em matéria de Meio Ambiente é a Smart Regulation, que compreende náo apenas formas de controle direto, no sentido do comando e controle, mas também formas flexíveis, criativas e inovadoras de controle social, que poderiam ser aplicadas seja para particulares, seja para governos e terceiros envolvidos. A regulação smart ou inteligente é espécie de autorregulação e mesmo de regulação compartilhada (self-regulation ou co-regulation), utilizando tanto interesses comerciais quanto interesses de organizaçóes não governamentais, o que promoveria formas mais efetivas de regulação ambiental, ante os déficits regulatórios normalmente apresentados. Tal estratégia lograria retornos positivos, como o fato de encorajar third parties, a exemplo de empresas e organizaçóes não governamentais, a adotarem mecanismos de adesão aos comandos estatais (compliance). Traria custos mais baixos, além de aumentar a compliance das empresas com as regras legais já existentes, a partir de esquema win-win. Sobre o assunto: GUNNINGHAM, Neil; SINCLAIR, Darren. Designing Smart Regulation, Oxford: Clarendon Press, 1998. GUNNINGHAM, Neil. Beyond compliance: next generation environmental regulation. Melbourne: Australian Institute of Criminology, 2002. WOLF, Brian. Organized environmental crime: an analysis of corporate
} noncompliance with the law. Lewiston/Queenston/Lampeter: The Edwin Mellen Press, 2009.

6 A co-regulação possui como características a natureza contratual, o voluntarismo e a cooperação e tem como objetivos fazer cumprir os princípios do poluidor pagador, da responsabilidade partilhada e da prevenção. Sobre a co-regulação e sua forma de ação consubstanciada nos acordos voluntários, ver CABUGUEIRA, Manuel. Os acordos voluntários como instrumento de política ambiental. Porto: Editora Vida Econômica, 1999, Pagina: 56-65, 174-176. Também em DIAS, José Eduardo de Oliveira Figueiredo. A reinvençáo da autorizaçáo administrativa no direito do ambiente. Coimbra: Coimbra Editora, $1^{a}$ ed., 2014, p. $930-956$.

7 Importante ressaltar que alguns ambientalistas criticam este tipo de soluçáo baseada em instrumentos de mercado ou que envolvam entidades empresariais, sendo conhecidas como "forma de greenwashing", termo criado por Jay Westervelt em 86.

8 Sobre os voluntaty environmental agreements na Uniáo Europeia. Disponível em: <http://ec.europa. eu/reducing_co2_emissions_from_cars/doc_contrib/beuc_voluntary_environmental_agreements_en.pdf>, acesso em 15 de março de 2016.

9 MAZZILLI, H. N. Compromisso de ajustamento de conduta: evolução e fragilidades e atuação do Ministério Público. In: Revista de Direito Ambiental, vol. 41, Jan/2006, DTR\2006125, p. 93. 
Para isso, em primeiro lugar será feito uma introdução reflexiva sobre o lugar do direito na proteção do ambiente ${ }^{10}$, em seguida um enquadramento teórico dos acordos voluntários ambientais na comunidade europeia. Passando a uma análise da aplicação concreta dos acordos no ordenamento brasileiro, abordando questóes relacionadas com essa implementação. Por fim, uma análise crítica e avaliativa de sua efetividade na promoção do princípio do acesso à Justiça, da participação do cidadão e do fortalecimento da democracia.

A metodologia utilizada na pesquisa consiste na análise exploratória e descritiva sobre o objeto de estudo, por meio de levantamento bibliográfico. Como resultados, buscase mostrar o compromisso de ajustamento de conduta como mecanismo alternativo na solução dos conflitos ambientais, objetivando soluçóes mais céleres e eficazes, haja vista a relevância dos bens ambientais no Estado Democrático de Direito, bem como a percepção do meio ambiente ecologicamente equilibrado como um bem ambiental de todos.

\section{OS ACORDOS VOLUNTÁRIOS AMBIENTAIS NA UNIÁO EUROPÉIA}

Os instrumentos da política ambiental como os acordos voluntários possuem um conteúdo importante na regulamentaçáo ambiental, e continuam a evoluir e mudar em consonância à experiência da gestão ambiental humana ${ }^{11}$. A partir dos anos 1970, o command and control, através da política de regulação ambiental e da política de incentivo econômico orientado para o mercado, desempenhava um papel efetivo no controle da proteção do ambiente.

Entretanto, ao longo do tempo, essas políticas se tornaram insuficientes, e o surgimento da gestão ambiental voluntária tornou-se inevitável. Os acordos voluntários possibilitam uma maior aproximação entre o Estado e os agentes poluidores, e caracterizam-se por uma certa flexibilidade, elemento fundamental quando se trata de problemas complexos com vários agentes econômicos.

É difícil encontrar na literatura um consenso quanto à definição de acordos voluntários, mas pode ser genericamente descrito como um acordo informal, criado por via consensual entre governo e indústria, visando a reduçáo das diversas consequências ambientais do desrespeito de regras relativas ao processo de produção, ao uso de energia ou aos pro-

10 Em atenção ao livro com o mesmo título de Maria da Gloria Garcia, O lugar do direito na proteção do ambiente, Almedina, Coimbra, 2007. Através de uma via pluridimensional e realista, a autora faz consideraçóes sobre os perigos éticos, políticos, sociais, econômicos e científicos que hoje rodeiam a construção do chamado "Estado Ambiental". Defende um direito do ambiente condicionado a decisáo politicamente legitimada, cientificamente fundada, tecnicamente adequada, economicamente eficiente e eticamente sustentada.

11 GOMES, C. A. DIAS, J. E. F. Notas reflexivas sobre sistemas de gestão ambiental. In: Revista do Centro de Estudos de Direito do Ordenamento, do Urbanismo e do Ambiente. No 31, Ano XVI, 1.2013, p. 9-27. 
dutos $^{12}$. Logo, os acordos voluntários ambientais possuem como objetivo melhorar o desempenho dos atores e a efetividade da política ambiental, através de um acordo informal e consensual entre governo e indústria. Acrescenta Ortiz e Solano que:

a doutrina identificou dois tipos de acordos voluntários: os primeiros considerados como verdadeiras formas de auto-regulação ou acordos voluntários (acordos de cavalheiros) e a segunda categoria, comumente desenvolvida nos Estados Unidos, que correspondem aos acordos para os quais o legislador estabeleceu as bases da regulamentação, determinando os objetivos e mecanismos de sua implementação, bem como as possíveis sançóes para garantir o cumprimento. Esta segunda categoria corresponde a uma manifestação de co-regulaçáo entre governo e indivíduos, no desenvolvimento das obrigaçóes encarregadas do último ${ }^{13}$.

Garcia afirma que os Acordos Ambientais, designadamente os contratos de adaptação ambiental ${ }^{14}$, além de introduzirem justiça na lei, mediante a negociação dos termos de seu cumprimento, indicam que a norma ambiental náo pode ser cumprida por todos igualmente, demonstrando um desejo de incentivar e premiar a diferença ${ }^{15}$. Assim os incentivos que movem os agentes econômicos a implementar acordos voluntários derivam do fato de estes se basearem no consenso, na parceria, na busca de benefícios comuns, na rápida implementação e por encorajarem o progresso técnico.

As indústrias, de um lado, veem neles a possibilidade de evitar uma legislação coercitiva, pois permitem atingir objetivos ambientais de forma mais flexível, melhorando simultaneamente a sua imagem quando envolvida em infraçóes ambientais e estimulando a procura, principalmente, dos denominados consumidores verdes ${ }^{16}$. Já as autoridades, por outro lado, veem nos acordos voluntários uma oportunidade de reduzir a assimetria de informação por parte das empresas, e de aumentar a eficiência da legislaçáo ambiental.

O objetivo de qualquer política implementada pelo Governo na área do ambiente é a redução da poluição ao menor custo possível. Deste modo, é importante que sejam cumpridas as condiçóes estabelecidas e de forma transparente, permitindo uma maior influência/ participação dos grupos de interesse nas negociaçóes. A ameaça de uma possível legislação fortalece o poder de negociação das autoridades públicas, o que possibilita atingir objeti-

12 BAILEY, P. M. The Creation and enforcement of environmental agreements, In: European Environmenatl Law Review, jun., vol.8, n. ${ }^{\circ} 6.1999$, p.171.

13 Ortiz, I. y Solano, D. La Libre Competencia Económica y la Protección del Medio Ambiente: Una aproximación al estudio de los Acuerdos Voluntarios de Cumplimiento Ambiental. In: Revist@ E-Mercatoria, vol. 15, $\mathrm{N}^{\circ} 1$, enero-junio, 2016, p. 21.

14 Termo utilizado em Portugal.

15 GARCIA, M. da G. O lugar do direito na proteçáo do ambiente. Coimbra: Ed. Almedina, 2007, p. 407 e ss.

16 Consumidores que estão dispostos a pagar um preço superior por um bem mais ecológico. PAIVA, Teresa Maria Dias de. O modelo de comportamento dos consumidores “verdes” portugueses: uma análise crítica. Tese de doutoramento em Marketing apresentada ao Instituto Superior das Ciências do Trabalho e da Empresa. Lisboa, 2003. 
vos mais ambiciosos no âmbito dos acordos voluntários.

A aplicação dos acordos voluntários no âmbito da política ambiental europeia, emanada dos órgãos comunitários, vinha sendo muito limitada ${ }^{17}$. Com efeito, estes poderiam apenas tomar a forma de compromissos unilaterais se reconhecidos pela Comissão e fossem não vinculativos ${ }^{18}$. Assim, é fácil compreender que a utilização de acordos pela Comissão só poderia ser efetuada em determinados casos e náo como um instrumento amplamente generalizado e fundamentado nas disposiçóes do Tratado da CE.

No entanto, existem outras dificuldades que limitam a aplicação dos acordos voluntários a nível comunitário como, por exemplo, a enorme dimensão dos processos, a questão de como reunir todos os envolvidos/interessados, o problema de possíveis freeriders ${ }^{19}$ e a verificação do cumprimento do acordo. Também estes acordos tendem a incluir a participação do Governo e/ou das empresas, excluindo terceiros como o Parlamento, grupos ambientais e sindicatos da elaboraçáo cooperativa dos processos. O que poderia pôr em causa a legitimidade dos acordos voluntários.

Os acordos voluntários só recentemente ganharam expressão no âmbito da política comunitária de ambiente, sendo, inclusive, reconhecidos e apoiados pelos órgãos da União Europeia. No entanto, com o crescente uso desta medida de proteção ambiental, começam a verificar-se alguns conflitos entre os acordos voluntários e a defesa da concorrência ${ }^{20}$. Uma vez que a obrigação de proteção ambiental constitui um encargo acrescido para a indústria, a eventual exoneração de alguns desses custos poderá ser considerada uma violação das regras de concorrência.

17 Segundo a Comunicação da Comissão Europeia de 1996, os acordos não podem ser utilizados como instrumentos de política em sentido estrito, uma vez que não se tratam dos instrumentos vinculativos explicitados no Tratado da CE. Comunicado da Comissáo Europeia ao Parlamento Europeu e ao Conselho de Ministros sobre os Acordos Voluntários, a 27 de Novembro de 1996. Disponível em: <http:// europa.eu/rapid/press-release_PRES-97-204_pt.htm>, acesso em 30 de junho de 2016.

18 No entanto, torna-se necessário referir o caso específico holandês, na medida em que representa cerca de um terço de todos os acordos voluntários negociados da UE e preconiza uma tipologia perfeitamente oposta à da generalidade dos países-membros. Com efeito, os acordos negociados na Holanda são independentes em relação à legislação nacional, pressupóem uma responsabilização individual e são vinculativos. Por outro lado, enquanto que nos outros países os acordos negociados sáo utilizados de uma forma selecionada, na Holanda cobrem todo o tipo de problemas ambientais, constituindo o instrumento de política ambiental fundamental neste país, apoiado por uma forte estrutura legal. Vide em MAÇÃS, Maria Fernanda. Os acordos sectoriais como um instrumento da política ambiental. In: Revista do Centro de Estudos de Direito do Ordenamento, do Urbanismo e do Ambiente. Ano III, 1. 2000, p. 41.

19 O efeito de boleia, para maior detalhamento vide GARCIA, Maria da Gloria F.P.D. O lugar do direito na protecçáo do ambiente. Coimbra: Ed. Almedina, 2007, P. 167-168.

20 Segundo o artigo $81^{\circ}$, número 1 , do Tratado da C.E., é proibido qualquer acordo ambiental que envolva empresas ou associaçóes de empresas e que tenha "por objetivo ou efeito impedir, restringir ou falsear a concorrência no mercado comum", conforme conclusões do advogado-geral Wahl apresentadas em 21 de Maio de 2015. AC-Treuhand AG contra Comissão Europeia. Recurso de decisão do Tribunal Geral. Processo C-194/14 P. Disponível em: <http://eur-lex.europa.eu/legal-content/PT/TXT/?uri=CELEX\%3A62014CC0194>, acesso em 30 de junho de 2016. Embora não seja provável que um acordo ambiental tenha o objetivo de restringir a concorrência, é evidente que pode ter o efeito mencionado. Assim, são medidas as restriçóes à concorrência impostas pelo acordo e comparadas com o valor dos benefícios ambientais alcançados, no sentido de decidir quanto à validade do mesmo acordo. 
Na maioria dos Estados-membros da União Europeia, ainda se utilizam instrumentos de política ambiental tradicionais de mercado (negociação de licenças) ou fiscais (utilização de impostos), relativamente mais rígidos quando comparados com os acordos voluntários. Assim, é do interesse geral que sejam desenvolvidas novas abordagens que fomentem a cooperação entre as indústrias e as autoridades públicas, isto é, que se propague a utilização de acordos voluntários no âmbito comunitário.

Em conformidade com o artigo $11 .^{\circ}$ do TFUE, as regras e os princípios para a proteção do meio ambiente devem ser integrados com as políticas econômicas da União Européia gerando um amalgama legal cuja consequência imediata e necessária é a geração de um cenário de Desenvolvimento sustentável da Comunidade.

Nesta direção, sua consolidação se deu com base no Quinto Programa Comunitário de ação em matéria de Ambiente da Comissão Europeia de 1992 - Em direção a um desenvolvimento sustentável, programa que defende a adoção de uma abordagem global e voluntarista, que inverta as tendências atuais de degradação do ambiente, definindo a partilha de responsabilidades e a utilização de novos instrumentos, nomeadamente os acordos voluntários ${ }^{21}$.

Seguindo o mesmo rumo, o Sexto Programa de Ação em Matéria de Ambiente - Ambiente 2010: o nosso futuro, a nossa escolha - sustenta que, para enfrentar os desafios dos problemas ambientais da atualidade, não se pode limitar a uma abordagem legislativa e defende que os novos métodos de governância, alternativos à regulamentação tradicional, tais como os Acordos Ambientais, são aptos a melhorar a capacidade de inovaçáo das empresas.

Observa-se que a Comissão Europeia (CE) vem reconhecendo a necessidade de alargar o conjunto de instrumentos de política ambiental utilizados na Uniāo Europeia, defendendo ainda que os acordos voluntários possuem um papel vital neste processo ${ }^{22}$. Assim, aborda as vantagens e riscos da utilização dos acordos voluntários, como encorajar uma aproximação com a indústria, ao dar uma certa liberdade no estabelecimento de objetivos ambientais, permitindo uma maior contabilização dos gastos e tempo necessário para o cumprimento das metas estipuladas.

O conhecimento das questões ambientais por parte dos cidadãos é também importante, já que pode incentivar ambas as partes do acordo a tomarem um papel mais proativo e

$21 \quad$ Fifth European Community environment programme: towards sustainability. Disponível em: <http://eur-lex.europa.eu/legal-content/PT/TXT/?uri=uriserv:128062>, acesso em 30 de junho de 2016.

22 Em Portugal, os acordos foram objeto de reformulação para garantir sua eficácia e o alcance dos objetivos ambientais. Os Contratos de Adaptaçáo Ambiental são verdadeiros contratos com obrigaçóes bem definidas para as partes, cominando sançôes para o não cumprimento das prescriçóes e um cronograma de adaptação, conforme previstos no Capítulo V, art. 35, $\mathrm{n}^{\circ}$ 2, da Lei de Bases do Ambiente e no art. $41^{\circ}$ da Lei n50/2006 que possibilita a substituição de medidas cautelares por contratos-programa. Logo, por se tratar de medidas cautelares, a substituiçáo ocorreria em um momento inicial do procedimento administrativo e não implicaria necessariamente a ocorrência de situaçóes consideradas pela lei "graves" ou "muito graves", mas somente por estar em causa, em alguma medida, o ambiente. MELLO, Roberta Corrêa Vaz de. Acordos ambientais: um panorama luso-brasileiro. In: Revista do Centro de Estudos de Direito do Ordenamento do Urbanismo e do Ambiente (CEDOUA), Coimbra, a. XIV, n. 27, p. 101-121, 2011, p. 105 e 112. 
célere na resolução dos problemas. Contudo, ressalta-se que a ausência de critérios de fiscalização e de sançóes no caso de incumprimento podem incentivar o náo cumprimento do acordo. Sendo assim, os próprios acordos devem ser orientados de forma que sejam efetivamente cumpridos, recorrendo-se a mecanismos tais como pressáo pública e ameaça de uma nova legislação ambiental.

Como vantagens, a doutrina e as instituiçóes europeias ${ }^{23}$ elencam que esses acordos, através da co-regulação, constituem uma extensão de padróes em áreas inalcançáveis pelas autoridades ou que extrapolassem a capacidade de ressarcimento por parte do poluidor. Destarte, permitem ainda que as partes envolvidas, por saberem o custo-benefício da implementação de um política ambiental, estabeleçam de forma ponderada, o alcance de seus compromissos, mediante os seus próprios limites.

\section{ACORDOS AMBIENTAIS NA LEGISLAÇÃO BRASILEIRA: COMPROMISSO DE AJUSTAMENTO DE CONDUTA}

O compromisso de ajustamento de conduta é uma solução extrajudicial de conflito de direitos transindividuais ${ }^{24}$, surgido no mesmo contexto da Constituição Federal de 1988, um momento de redemocratização das instituiçôes e de adaptação do ordenamento jurídico. Essa inovação no sistema jurídico brasileiro permitiu uma nova amplitude de atuação do Ministério Público e por outros órgãos públicos para compor conflitos relativos a direitos indisponíveis.

Procura-se nesta composição uma participação negociação ${ }^{25}$, adequando a conduta do cidadão desviada a evitar ou reparar um dano ao interesse público. Ressalta-se que na área ambiental a conciliação dos interessados é fase valiosa, havendo inclusive, segundo Michel Prieur, um princípio de "négociation avec les pollueurs"26.

Dessa forma, conjugadas a previsão de eficácia executiva de acordos celebrados pelo Mi-

23 Ortiz, I. y Solano, D. "La Libre Competencia Económica y la Protección del Medio Ambiente: Una aproximación al estudio de los Acuerdos Voluntarios de Cumplimiento Ambiental”. In: Revist@ E-Mercatoria, vol. 15, $\mathrm{N}^{\circ} 1$, enero-junio, 2016, p. 22.

$24 \quad \mathrm{O}$ ajuste de conduta é um instituto estabelecido em favor da tutela dos direitos transindividuais, ou seja, náo é finalidade da norma favorecer o violador do direito. Neste sentido, a realização do termo de ajuste de conduta tem que ocorrer à luz do fim da norma, ou seja, só deve ocorrer quando se revelar a melhor solução para a tutela do direito ambiental (CARNEIRO, Paulo Cézar Pinheiro. A proteçáo dos direitos difusos através do compromisso de ajustamento de conduta previsto na lei que disciplina a açáo civil pública. Tese aprovada no 90 Congresso Nacional do Ministério Público, em Salvador, 1992, p. 237).

25 ANTUNES, L. F. C. A tutela dos interesses difusos em direito administrativo. Para uma legitimação procedimentel. Coimbra: Almedina, 1989.

$26 \quad$ Prieur ensina que a política ambiental se caracteriza pelo seu caráter pedagógico. É necessário convencer e persuadir, em vez de apenas obrigar os poluidores a cessarem suas atividades nocivas. Embora a legislação ambiental seja essencialmente um regime policial destinado a limitar ou proibir a poluição por atos unilaterais autoritários, a realidade administrativa é favorecida por medidas concertadas e negociadas com a indústria. Porém, deve ser permitida se for acompanhada de controle. PRIEUR, Michel. Droit de l'environnement. Paris: Dalloz, 2001, p. 116. 
nistério Público e por outros órgãos legitimados, a experiência da prática administrativa concertada, a possibilidade de composiçấo de direitos transindividuais indisponíveis e a adequação da tutela extrajudicial desses direitos, tem-se a concepção do instituto do termo de ajustamento de conduta ${ }^{27}$.

Dentre os princípios regulatórios do ajustamento de conduta, tem-se o princípio do acesso à justiça, ao conceber um novo mecanismo de composição de conflitos envolvendo direitos transindividuais complementares à atividade jurisdicional; o princípio da tutela preventiva, que preconiza que sempre que possível o sistema jurídico deve evitar a ocorrência dos atos ilícitos e dos danos, inclusive em muitas situaçóes estabelece uma forma de promover a justiça coexistencial ${ }^{28}$; o princípio da tutela específica, por privilegiar a tutela preventiva de direitos, ou seja, tutela plenamente adequada para a satisfaçáo dos deveres jurídicos para com uma comunidade; a aplicaçáo negociada da norma jurídica, uma vez que o conflito de interesses entre, por exemplo, a proteção de um ecossistema e a manutenção da atividade econômica que o ameaça, exige do juiz uma nova responsabilidade, logo a informalidade presente na possibilidade de negociação é altamente compatível com a construção da forma mais efetiva de proteção dos direitos transindividuais; o princípio democrático, posto que é um meio de se honrar os fundamentos do Estado Democrático de Direito, desde que sejam incluídos mecanismos de participação daqueles afetados e a obrigação de transparência dos atos ou procedimentos administrativos relacionados a tais $\operatorname{acordos}^{29}$.

O compromisso de ajustamento de conduta não foi introduzido no Direito Brasileiro pela Lei de Ação Civil Pública (Lei nº7.347/85), mas surgiu alguns anos depois, já no início da década de 1990, primeiro quando da edição do Estatuto da Criança e do Adolescente e, em seguida, do Código de Defesa do Consumidor que o inseriu na Lei de Ação Civil Pública. ${ }^{30} \mathrm{Com}$ isso, os órgãos públicos legitimados à ação civil pública ou coletiva ${ }^{31}$ pas-

27 RODRIGUES, G. de A. Princípios da celebração do compromisso de ajustamento de conduta em matéria ambiental. In: Revista do Centro de Estudos de Direito do Ordenamento, do Urbanismo e do Ambiente. No 13, ano VII, 1.2004, p. 69-70.

28 SANTOS, B. de S. O Direito e a comunidade. As transformaçóes recentes da natureza do poder do Estado nos países capitalistas avançados. In: Revista Direito e Avesso, Brasília, col. II, no 3, p.138-156, jan/jul. 1983, p. 139.

29 Sobre os princípios regulatórios do compromisso de ajustamento de conduta. RODRIGUES, Geisa de Assis. Princípios da celebração do compromisso de ajustamento de conduta em matéria ambiental.

In: Revista do Centro de Estudos de Direito do Ordenamento, do Urbanismo e do Ambiente. No 13, ano VII, 1.2004, p. 72-87.

30 Conforme Hugo Nigro Mazzilli (Compromisso de ajustamento de conduta: evolução e fragilidades e atuação do Ministério Público. In: Revista de Direito Ambiental, vol. 41, p. 93, Jan/2006, DTR 2006 125, p. 2, nota de rodapé no2) em que destaca ainda que o art. 211 da Lei n. 8.069, de 13 de julho de 1990 (Estatuto da Criança e do Adolescente) introduziu o compromisso de ajustamento de conduta em matéria de defesa de interesses das crianças e adolescentes; logo depois, o art. 113 da Lei n. 8.078, de 11 de setembro de 1990 (Código de Defesa do Consumidor) inseriu o $\$ 6^{\circ}$ ao art. 5 da Lei n. 7.347, de 24 de julho de 1985 (Lei da Ação Civil Pública), por meio do qual o compromisso de ajustamento de conduta passou a ser admissível em matéria referente a quaisquer interesses transindividuais, sejam relativos ao consumidor ou não.

$31 \quad$ A legitimidade é conferida ao Ministério Público, Defensoria Pública, União, Estados, Distrito Federal, Municípios, autarquias, empresas públicas e fundaçôes ou sociedades de economia mista. 
saram a poder tomar do causador de danos a interesses difusos e coletivos o compromisso escrito, chamado termo de ajustamento de conduta (TAC).

Conforme previsto no art. $5^{\circ}, \$ 6^{\circ}$, da Lei n. $7.347 / 85$, o compromisso de ajustamento de conduta é lavrado em termo, contendo uma obrigação de fazer ou não fazer e é tomado por um dos órgáos públicos legitimados à propositura da ação civil pública ou coletiva. Mediante esse instrumento, o causador do dano a interesses transindividuais (meio ambiente, consumidor, patrimônio cultural, ordem urbanística etc.) se obriga a adequar sua conduta às exigências da lei, sob pena de cominaçóes já pactuadas no próprio instrumento, o qual terá força de título executivo extrajudicial.

Tanto a doutrina como a jurisprudência do Superior Tribunal de Justiça têm aceitado a validade do compromisso de ajustamento, o qual vem sendo aplicado desde 1990 pelo Ministério Público e pelos demais órgãos públicos legitimados à ação civil pública. E isso se faz com grande proveito social, já que os compromissos de ajustamento de conduta são consensuais, visam à defesa de interesses transindividuais, evitam milhares de açóes individuais, e, mantem a possibilidade de que os co-legitimados e os lesados individuais, caso discordem dos ajustes, compareçam a juízo em busca do que entenderem devido.

O compromisso de ajustamento de conduta não tem natureza contratual ${ }^{32}$, pois os órgãos públicos que o tomam não têm poder de disposição. Assim, o compromisso de ajustamento de conduta pode ser considerado um negócio jurídico bilateral, que consubstancia uma declaração de vontade do Poder Público coincidente com a do particular, causador do dano. Por conseguinte, os órgáos públicos legitimados não podem dispensar direitos ou obrigaçóes, nem renunciar a direitos, mas devem limitar-se a tomar, do causador do dano, obrigação de fazer ou não fazer e podem estipular cláusulas compensatórias como garantias mínimas ${ }^{33}$.

Tendo em vista sua natureza negocial, o compromisso de ajustamento de conduta se desconstitui pelas mesmas vias com que foi feito ou por via judicial, pelos vícios do ato jurídico em geral ${ }^{34}$. Por via consensual, pode ser recompromissado, desde que advenha fato novo, ou se o causador do dano aceder em ampliar suas próprias obrigaçóes em proveito do grupo lesado. O que não se admite é que qualquer co-legitimado público reduza ou dispense as exigências já constantes de compromisso tomado por um co-legitimado. Uma vez celebrado o compromisso de ajustamento de conduta, apenas fica vedado o acesso jurisdicional para todos os co-legitimados coletivos pedirem aquilo que o título já lhes dá,

32 Embora a doutrina não tenha um entendimento pacifico a respeito da natureza jurídica do compromisso de ajustamento de conduta, se seria entendido como transação, negócio jurídico ou contrato, tendo sido objeto de estudo de Ana Luiza de Andrade Nery, em Compromisso de Ajustamento de Conduta: teoria e análise de casos práticos. São Paulo: Ed. RT, 2010, entendemos que o mais adequado seria considerá-lo negócio jurídico bilateral, em consonância ao pensamento de Milaré, pois a bilateralidade é fundamental na celebração do ajuste, devendo haver manifestação coincidentes, reciprocas e concordantes de ambas as partes em prol da proteção do meio ambiente (MILARÉ, Edis. Direito do ambiente. 10a edição revista, atualizada e ampliada. São Paulo: RT, 2015 p. 1468 e 1469).

33 MELLO, R. C. V. de. Acordos ambientais: um panorama luso-brasileiro. In: Revista do Centro de Estudos de Direito do Ordenamento do Urbanismo e do Ambiente (CEDOUA), Coimbra, a. XIV, n. 27, p. 101-121, 2011, p. 114.

34 Vícios do negócio jurídico constantes do art. 117 do Código Civil Brasileiro. 
porque, nesse caso, lhes faltaria interesse de agir.

O causador do dano pode ser executado em caso de inadimplemento da obrigaçáo assumida, seja porque não a cumpriu na forma prevista, seja porque não observou o prazo pactuado ${ }^{35}$. Consoante o $\$ 6^{\circ}$ do art. $5^{\circ}$ da Lei $7.347 / 1985$, são previstas cominaçôes em caso de descumprimento da obrigação ${ }^{36}$. $\mathrm{O}$ compromisso de ajustamento também não pode gerar qualquer limitação máxima de responsabilidade material do causador do dano, pois isso poderia prejudicar os verdadeiros lesados.

A eficácia do compromisso de ajustamento inicia-se no momento em que o órgão público legitimado toma o compromisso, independentemente de qualquer outra formalidade, que a lei federal, aliás, não impôs. É frequente, pois, que os interessados pactuem no próprio instrumento o início, o termo, as condiçóes ou os prazos para que seja cumprido o compromisso de ajustamento.

As vantagens em comparação com a ação civil pública estão ligadas à permissão de uma soluçấo negociada para grande parte das lesóes transindividuais, ajudando a descongestionar a Justiça, evitando a lentidão dos mecanismos formais de justiça, e até mesmo, poder evitar a ocorrência de dano. Assim, tem-se a regência do princípio da prevenção, garantindo eficaz acesso dos lesados à tutela individual e coletiva de seus interesses. Além disso, o ajuste é menos oneroso, pois não pressupóe recolhimento de custas ou taxas.

Com efeito, quando o Compromisso de ajustamento de conduta tem por objeto a proteção ambiental, esse instrumento se mostra eficaz, principalmente, ante a morosidade dos processos judiciais. Isto porque, o TAC traz vantagens e se mostra adequado e eficiente quando, por exemplo, uma indústria que se compromete em corrigir em tempo razoável a emissão de sons e ruídos que estão causando incômodos e danos à saúde da vizinhança ${ }^{37}$.

Também são considerados benéficos pela parte poluidora, porque acarretam uma maior consciência da realização do possível através da assunção voluntária e consciente da obrigação, possibilitando um aprendizado ambiental e a preservação da imagem e da marca da empresa. Importante ainda, o estabelecimento na convenção de condiçóes de cumprimento das obrigaçóes no que se refere a modo, tempo, lugar, considerando as peculiaridades do caso concreto, a capacidade econômica do infrator e o mínimo para sua manutenção e o interesse da sociedade.

\footnotetext{
35 Vide como exemplo acórdão do STJ: REsp 1333251/RS, com relatoria do Ministro Hermam Benjamin, DJe 05/05/2017.

36 MILARÉ, Edis. Direito do ambiente. $10^{\text {a }}$ edição revista, atualizada e ampliada. São Paulo: RT, 2015, p. 1472.

37 AKAOUI, F. R. V. Compromisso de ajustamento de conduta ambiental. São Paulo: Editora Revista dos Tribunais, 2003, p.106.
} 


\section{A QUESTIONÁVEL EFETIVIDADE DA REGULAMENTAÇÃO AMBIEN- TAL: ACESSO À JUSTIÇA E PARTICIPAÇÃO DEMOCRÁTICA}

A título de exemplificação e não menosprezando os danos ambientais advindos de outras atividades industriais e de produção, parte-se o raciocínio a partir da análise dos impactos da mineração no Brasil ${ }^{38}$. Os quase 500 anos da atividade no território brasileiro deixaram grandes passivos ambientais, envolvendo milhares de minas e garimpos. Há também diversos tipos de conflitos socioambientais ${ }^{39}$, envolvendo populaçóes tradicionais como índios, quilombolas e populaçôes ribeirinhas; populaçóes atingidas pela instalação de megaprojetos de mineração, populaçóes afetadas pela contaminação decorrente da extração mineral, além de conflitos decorrentes da oposiçấo de interesses e da visão divergente sobre o que é desenvolvimento, especialmente em áreas de grande riqueza natural e com potencial turístico e áreas de concentração populacional.

No início de junho do corrente ano, a Comissão Interamericana denunciou o Brasil à OEA por casos como o de Mariana e outros $12^{40}$, nos quais há desrespeito aos direitos humanos causados por atividades mineradoras no país ${ }^{41}$. Também foram condenados os retrocessos trazidos pelas alteraçóes legislativas que o PLS 654/2015 e a PEC 65/2012 que pretendiam introduzir como a flexibilização do licenciamento ambiental ${ }^{42}$.

Observa-se, geralmente, uma dependência das comunidades das áreas de mineração com relação a este setor econômico, uma vez que as condiçóes de pobreza e desigualdade social são usadas como facilitadores da ação das empresas, pois sob tais condiçôes há uma tendência à população aceitar mais facilmente os impactos negativos da atividade minerária. Além disso, verifica-se que sua estrutura econômica se centra no atendimento das demandas diretas e indiretas para o funcionamento da exploração minerária.

Desse modo, as cidades e vilas onde se encontram instaladas as empresas mineradoras tornam-se reféns dessa atividade econômica, considerando um privilégio contar com os recursos provenientes da arrecadação pela presença deste setor no território. Entre as violaçôes denunciadas estão a ausência de assistência emergencial às vítimas, o não cumpri-

\footnotetext{
38 Desde o desastre em Mariana, houve um aumento da preocupaçáo ambiental com as formas de prevenção e reparação dos danos provocados pela atividade minerária.

39 ARAÚJO, E. R.; FERNANDES, F. R. C. Mineraçáo no Brasil: crescimento econômico e conflitos ambientais. In: Conflitos ambientais na indústria mineira e metalúrgica: o passado e o presente. Edição: Centro de Investigaçáo em Ciência Política (CICP), Portugal; Centro de Tecnologia Mineral, Ministério da Ciência, Tecnologia e Inovação (CETEM/MCTI), Brasil, Evora e Rio de Janeiro, 2016., p. 75.

40 Comissão Interamericana denuncia Brasil à OEA por tragédia em Mariana. El Pais. Disponivel em $<$ http://brasil.elpais.com/brasil/2016/06/07/politica/1465319140_029773.html>, acesso em 30 de junho de 2016.

41 Sobre a denúncia do Brasil à OEA, vide informe completo apresentado da Solicitação de Audiência Temática: Afetaçôes aos Direitos Humanos devido à Mineraçáo no Brasil. Conectas. Disponível em $<$ http://www.conectas.org/arquivos/editor/files/informe_audiência-mineração\%20revisado.pdf>, acesso em 28 de junho de 2016.

42 Em que pese as contestaçóes dos ambientalistas, no dia 03 de março de 2018, foi publicado no Diário Oficial de Minas Gerais o Decreto estadual no 47.383, que substitui na íntegra o Decreto estadual no 44.844/2008, com mecanismos de flexibilização ou facilitação do licenciamento ambiental.
} 
mento do dever de informação e violação dos direitos à água, à saúde, à moradia, à vida e à integridade física, além de violaçóes a outros direitos econômicos sociais e culturais.

$\mathrm{Na}$ atualidade, a busca pelo acesso à justiça e a participação pública é crescente e constante. Sendo uma tendência mundial, no ordenamento brasileiro, o legislador, através da Lei da Ação Civil Pública e do Código de Defesa do Consumidor, vem demonstrando uma preocupação com a defesa de direito transindividuais, facilitando e incentivando a tutela ambiental, por meio, por exemplo, da inversão do ônus da prova, da dispensa de quaisquer despesas e da não condenação da associação autora, ressalvada a comprovação de má-fé.

Para garantir o princípio do livre acesso à justiça, o Estado deve providenciar mecanismos adequados, de modo a encorajar a defesa dos interesses coletivos e difusos. Neste sentido, o artigo 25 da Convenção Americana (Online, 1969) sobre os Direitos Humanos, ao tratar da proteção judicial, ressalta:

Art. 25. Toda pessoa tem direito a um recurso simples e rápido ou a qualquer outro recurso efetivo, perante os juízes ou tribunais competentes, que a proteja contra atos que violem seus direitos fundamentais reconhecidos pela Constituição, pela lei ou pela presente Convenção, mesmo quando tal violação seja cometida por pessoas que estejam atuando no exercício de suas funçóes oficiais.

No entanto, diante da crise do Poder Judiciário, marcada pela morosidade, falta de efetividade, de credibilidade na maioria dos casos concretos submetidos a sua apreciação, decorre a necessidade urgente de medidas alternativas na solução dos conflitos em geral e, em especial, os de raiz ambiental, por envolver direitos fundamentais de terceira dimensão, como o meio ambiente, que é imprescindível para as presentes e futuras geraçôes.

Em situação de desastres ambientais de grande dimensão como o ocorrido na cidade de Mariana em Minas Gerais em 2015, nota-se que são interpostas uma multiplicidade de açóes tratando do mesmo tema, cada uma ao seu modo, mas todas buscando o ressarcimento dos prejuízos causados à coletividade. Ocorre que a existência de tantas açóes judiciais, muitas com pedidos liminares, afasta a possibilidade de satisfação de todos os pedidos formulados contra os mesmos réus, em prejuízo da proteção dos bens jurídicos em questão. Podendo, inclusive, correr o risco de haverem sentenças conflitantes. 
Tal cenário de tumulto processual é característico desses casos, nos quais uma infinidade de agentes é atingida, repercutindo diretamente em várias esferas de interesse, que transcendem os prejuízos imediatamente apuráveis. Situação muito semelhante se deu com a explosão, no Golfo do México, da plataforma Deepwater Horizon, pertencente à Transocean e operada pela British Petroleum (BP) ${ }^{43}$. Da mesma forma, uma série de ações (civis e criminais) foram propostas contra a BP e outros corréus, seja por iniciativa de particulares ou pelos poderes públicos dos Estados Unidos, incluindo açóes individuais e coletivas.

Com o intuito de solucionar as perdas de ordem econômico-financeira, dentre outras reinvindicaçóes era necessário encontrar uma solução global para as açóes propostas. Assim, os entes da federação americana envolvidos entenderam por bem reunir todos os processos em um único juízo, a fim de buscar a composição de um acordo global, a ser submetido à homologação judicial. No total, essa solução chegou à cifra de mais de US $\$ 20$ bilhóes, sendo o mais caro acordo celebrado com uma única entidade da história do Departamento de Justiça dos EUA.

Tal qual se sucedeu no caso do Golfo do México, as causas envolvendo a Samarco e suas controladoras, tendo em vista a defesa de interesses coletivos, também demandariam uma análise completa, de modo a permitir um melhor aproveitamento do rito processual e esgotamento dos meios de prova, evitando-se, dessa maneira, a fragmentação da solução final. Logo, a solução mais adequada, em atendimento aos princípios da efetividade, economicidade e uniformização, seria a reunião de todas as açóes coletivas em um único juízo ${ }^{44}$.

No entanto, como visto, diante da crise dos meios tradicionais de acesso à justiça, pode

43 Em 20/04/2010, a uma distância de cerca de $80 \mathrm{~km}$ da costa do estado de Louisiana, o poço $M a$ condo sofreu uma ruptura catastrófica, causando um incêndio que perdurou por alguns dias. O acidente levou à morte onze homens a bordo e, por um período de quase três meses, foram sendo derramados mais de três milhões de barris de petróleo nas águas do Golfo, atingindo até $2.000 \mathrm{~km}$ da costa do Texas à Flórida. O óleo se espalhou por profundas correntes marítimas e chegou a centenas de milhas de distância do foço, produzindo manchas com mais de $110.000 \mathrm{~km}^{2}$ de extensão e depositando resíduos químicos em mais de $1.000 \mathrm{~km}^{2}$ do fundo do mar. Como resultado, a qualidade da água foi drasticamente afetada, expondo plantas aquáticas e animais selvagens a substâncias de alta nocividade. Em virtude do derramamento, foram danificadas atividades econômicas essenciais ao complexo regional, como a pesca, que ficou temporariamente paralisada. E ao olear centenas de milhas de praias, zonas húmidas costeiras, pântanos, foram exterminadas milhares de aves e outros animais marinhos, causando incalculáveis lesóes de ordem econômica e natural. U.S. and Five Gulf States Reach Historic Settlement with BP to Resolve Civil Lawsuit Over Deepwater Horizon Oil Spill. The United States Department of Justice. Disponível em: <http://www.justice.gov/opa/pr/us-andfive-gulf-states-reach-historic-settlement-bp-resolve-civil-lawsuit-over-deepwater>; Deepwater horizon. The United States Department of Justice. Disponível em <http://www.justice.gov/enrd/deepwater-horizon>, acessos em 25 de junho de 2016.

44 E é também seguindo essa mesma linha que o Novo Código de Processo Civil (Lei 13.105/15) estabeleceu mecanismos inovadores no trato da litigiosidade repetitiva e de massa. E para aprimorar ainda mais a resolução de problemas análogos, criou o chamado "incidente de resolução de demandas repetitivas" (IRDR), com previsão no Capítulo VIII do Título I do Livro III (artigos 976 e seguintes), por meio do qual poderá ser definido um padrão-decisório ou decisão-modelo, quanto à matéria de direito, a ser aplicado a casos idênticos. OLIVEIRA, F.A.R. Competência. In: THEODORO Jr., H.; OLIVEIRA, F.A.R.; REZENDE, E.C.G.N. (eds.). Primeiras liçóes sobre o novo direito processual civil brasileiro: de acordo com o Novo Código de Processo Civil, Lei 13.105, de 16 de março de 2015. Rio de Janeiro: Forense, 2015, p. 64-81, p. 76. 
ser mais proveitoso a utilização dos meios alternativos do que recorrer ao Poder Judiciário. Assim, procura-se a solução dos conflitos ambientais por meio de instrumentos como o TAC, mediante a comunicação, o diálogo e o entendimento. Por conseguinte, novas estratégias de solução dos conflitos efetivam o princípio do acesso à Justiça e redemocratizam a participação do cidadão e da comunidade. Neste sentido Fink apud Milaré vem ensinar que:

Antes de se lançar mão de tão desgastante, cara e difícil solução para o conflito ambiental, deve-se buscar a via da negociação, por meio da qual todos encontrarão seus lugares e ao final do processo sairão muito mais fortalecidos do que se fossem obrigados a obedecer um comando frio e inexorável de uma sentença ${ }^{45}$.

O Compromisso de ajustamento de conduta disposto na Lei n. 7.347/81 constitui-se exatamente como um meio alternativo de se alcançar a tutela jurisdicional, de forma a consolidar o acesso à Justiça no Estado Democrático de Direito. Os mecanismos de solução de conflitos como mediação, arbitragem, conciliação e o TAC são procedimentos voluntários, caracterizados pela informalidade, rapidez, participação da comunidade, com diálogo entre as partes, o que reflete maior inovação da política judiciária.

Além de prezar por uma composição em tempo suficiente, é fundamental a participação pública nos processos de tomadas de decisão pública ${ }^{46}$, que tenha transparência por meio de publicidade e que possibilite controle social. Em desastres de grandes dimensóes, ONGs como o Greenpeace, por exemplo, desenvolvem estudos das diferentes áreas afetadas pelo desastre como fauna, flora, água, impactos sociais e direitos humanos, pois incentivar a pesquisa na regiáo atingida por uma tragédia é um importante passo para dimensionar os efeitos da devastação.

Isso porque, especificamente, nas demandas relativas a conflitos ambientais, por sua natureza complexa, são envolvidos conhecimentos de áreas diversas do saber, podendo o acordo entre as partes ser realizado antes da Ação Civil Pública ou durante o curso desta. Acredita-se que a participação de experts seja substancial na elaboração do termo, para uma identificação mais precisa dos danos ambientais e a sua mensuração. Assim, o compromisso de ajustamento de conduta se apresenta como instrumento democrático complementar na resolução dos conflitos ambientais por meio de novas alternativas à jurisdição estatal.

Ressalta-se que embora a maioria dos Termos de ajustamento de conduta sejam firmados com o Ministério Público, a Defensoria Pública também possui plena legitimidade desde a edição da Lei 11.448/2007, que a incluiu entre os atores coletivos do rol previsto no

\footnotetext{
45 MILARÉ, E. Direito do ambiente. $10^{a}$ edição revista, atualizada e ampliada. São Paulo: Revista dos Tribunais, 2015, p. 1466.

46 Conforme artigo $41^{\circ}$ da Carta dos Direitos Humanos Fundamentais da União Europeia, a Declaração do Rio sobre Ambiente e Desenvolvimento, a Convenção de Aarhus, a participação pública é um dos elementos essenciais da democracia ambiental, integrantes de uma decisão responsável e atuação administrativa mais prudente. LOPES, Cristiana Maria Cardoso. "A legitimação participativa de uma decisão ambientalmente responsável” in Revista CEDOUA, no 29, Ano XV, 1.2012, p. 117-129.
} 
art. $5^{\circ}$ da Lei da Ação Civil Pública. Além disso, tendo a LC 132/2009 acrescentado funçóes relativas a tutela ambiental, a Defensoria, até que a ADIn 3.943-1 seja decidida ${ }^{47}$, pode e deve possibilitar a tutela dos necessitados ou quando a sua esfera jurídica possa ser atingida, ou seja, quando a tutela do bem jurídico esteja inserido no âmbito de sua competência.

Por fim, discute-se os modos de aperfeiçoar o acordo ambiental voluntário. Verificam-se como aspectos negativos a fraca participação popular na construção das soluçóes propostas ao envolver somente alguns atores em específico na sua propositura, o irrealismo dos prazos, demonstrando uma falta de atenção na elaboração do termo ou uma tentativa de burlar o cumprimento da legislação ambiental por parte do causador do dano. Além disso, a irrestrição no número de termos aditivos, a dilação dos prazos e a exclusão da sociedade no processo, pode ocasionar um efetivo dano ambiental ou seu alargamento, logo a inadequação entre o dano causado e a sanção aplicada, compromete a melhoria da qualidade ambiental. Em suma: deficiência na elaboração do TAC e faltosa ou deficiente monitorização ${ }^{48}$.

Em face da indisponibilidade do direito ao meio ambiente, a proposta do compromisso deve ser de reparação integral do dano. O que se admite são as condiçóes para o seu cumprimento, tendo em vista cada caso em concreto, a capacidade econômica do poluidor/ infrator e o interesse social. Em consonância à sumula 21, aviso 140/2004 do Conselho Superior do Ministério Público, é recomendável que o agente celebrante sempre fiscalize o cumprimento do TAC. Este acompanhamento deve ser periódico e requerido do compromitente a comprovaçáo do cumprimento das obrigaçóes assumidas, conforme os prazos estabelecidos sejam findados ${ }^{49}$ e diante de irregularidades, deve o órgáo público intimar o poluidor para esclarecê-las ou saná-las, conforme o caso.

Todavia, a celebração do TAC não esgota o processo de efetivação da norma. Como anota Milaré, a formalização dos termos de ajustamento deve primar pelos princípios regentes da Administração Pública e dependem de um mínimo de agilidade para ser eficaz e eficiente $^{50}$. Além disso, se o TAC é justificado como forma de atender ao caráter de urgência de ação contra as lesóes ou ameaças de lesóes aos direitos transindividuais, os seus prazos e seus termos aditivos não podem ser prorrogados indefinidamente. Irrelevante seria a existência de cláusulas referentes a cominaçóes em caso de descumprimento da obrigação assumida se houver a possibilidade de, a cada expiração do prazo de sua vigência, prorrogarem-se as obrigaçóes via sucessivos termos aditivos. Logo, para sua implementação é necessário um critério claro e objetivo para o estabelecimento de prazos e possibilidade

47 Em razão do dissenso relativo à legitimidade ativa da Defensoria Pública foi instaurada a ADIn 3.943-1 (MILARÉ, Edis. Direito do ambiente. 10a edição revista, atualizada e ampliada. São Paulo: RT, 2015, p. 1412).

48 Conforme estudo da real efetividade dos acordos ambientais realizado por Roberta Corrêa Vaz de Mello em A insônia da princesa da fábula: acordos ambientais e governância, dissertação de mestrado em Direito Administrativo na Faculdade de Direito da Universidade de Coimbra, Coimbra, 2009.

49 MILARÉ, E. Direito do Ambiente. 10a Edição Revista, atualizada e ampliada. São Paulo: RT, 2015, p. 1474-1475.

50 MILARÉ, E. Direito do Ambiente. 10ª Edição Revista, atualizada e ampliada. São Paulo: RT, 2015 , p. 1475 . 
de prorrogação.

Por fim, no que tange à participação popular, o órgão público legitimado que o propóe, pode criar possibilidades para um envolvimento direto por meio da inclusão, como partícipes do acordo, de representantes dos grupos sociais cujos interesses coletivos estejam envolvidos no TAC, ou condiçóes para um envolvimento indireto via controle social, por meio da garantia de uma correta e efetiva publicidade desse TAC.

\section{CONSIDERAÇÓES FINAIS}

Os acordos voluntários ambientais são um instrumento cujo âmbito de aplicação é relativamente recente, mas têm ganhado uma expressão notável, devido à especificidade que os caracteriza. De fato, a possibilidade de diálogo e cooperação entre empresas e Estado agrada a ambos os setores, pois constitui um grande avanço a composição extrajudicial de conflitos coletivos com defesa de interesses transindividuais. Assim, esta solução ganhou forma, permitindo maior flexibilidade e objetividade na resolução de problemas concretos.

Observa-se que tanto no âmbito europeu, como no ordenamento jurídico brasileiro, os institutos utilizados como meio de proteção do meio ambiente advêm da atual prática administrativa. Por conseguinte, através de negociação, são adotadas medidas sobre a forma de cumprimento de normas legais, visto que sem o ajuste das condiçóes de cumprimento das obrigaçóes impostas, o poluidor, muitas vezes, não teria possibilidades de cumprir o que lhe é imposto.

Os efeitos dos acordos voluntários revelam-se nas mais diversas esferas: competitividade das empresas, eficiência técnica, estrutura de mercado, influência sobre as decisóes do Estado, destacando a aplicação dos princípios da prevenção e da precaução no meio ambiente. Além disso, confrontado com a longa instrução probatória e prolação de sentença, o processo de restauraçáo ocorre de forma mais rápida, evitando inclusive o risco de decisōes conflitantes.

De forma geral, percebe-se uma preocupação no campo acadêmico, quase que exclusiva, sobre a incidência, o objeto e os legitimados para a propositura do TAC, sem, contudo, haver uma concreta avaliação sobre a implementaçáo e aperfeiçoamento do mesmo. Entretanto, apesar de suas deficiências, acredita-se na aptidão desses instrumentos como mediadores da necessidade de implementação da política ambiental e da possibilidade de cumprimento dessa política.

Para a sua real efetividade, resta aprimorar a elaboração do TAC e sua fiscalização. É importante a participação efetiva dos envolvidos no processo de implantação de um empreendimento, bem como na solução das violaçóes de direitos humanos dele decorrentes. Para a composiçáo do acordo, um certo grau de flexibilidade deve ser mantido, pois o êxito do compromisso depende da análise concreta de cada caso para uma justa ponderação. Portanto, a aplicação dos princípios de acesso à justiça, da participação social, de lealdade 
ao cumprimento do acordo e a fiscalização por parte do órgão público podem revelar o compromisso de ajustamento de conduta como um excelente mecanismo de defesa do ambiente.

As tendências recentemente evidenciadas apontam para uma maior exigência dos acordos voluntários, em termos de metas ambientais, bem como a afirmação do Estado como líder no estabelecimento dos objetivos dos acordos em detrimento das empresas. Num mundo cada vez mais consciente e atento no que diz respeito às questóes relacionadas com o meio ambiente, espera-se que os acordos voluntários possam constituir-se como um caminho viável e eficaz e não como uma saída mais fácil para empresas e governos.

\section{REFERÊNCIAS}

AKAOUI, F. R. V. Compromisso de ajustamento de conduta ambiental. São Paulo: Editora Revista dos Tribunais, 2003.

ANTUNES, L. F. C. A tutela dos interesses difusos em direito administrativo. Para uma legitimaçáo procedimentel. Coimbra: Almedina, 1989.

ARAGÃO, M. A. De S. O Princípio do nível elevado de proteção e a renovação ecológica do direito do ambiente e dos resíduos. Coimbra: Almedina, 2006.

ARAÚJO, E. R.; FERNANDES, F. R. C. Mineração no Brasil: crescimento econômico e conflitos ambientais. In: Conflitos ambientais na indústria mineira e metalúrgica: o passado e o presente. Edição: Centro de Investigação em Ciência Política (CICP), Portugal; Centro de Tecnologia Mineral, Ministério da Ciência, Tecnologia e Inovaçáo (CETEM/MCTI), Brasil, Évora e Rio de Janeiro, 2016.

BAILEY, P. M. Environmental Agreements and Compliance with the Treaty: Issues of Free Trade, Competition and State Aid. Brussels: CAVA Working Paper, 2000.

BAILEY, P. M. The Creation and enforcement of environmental agreements. In: European Environmenatl Law Review, jun., vol.8, nº 6, 1999.

BLACK, J. Critical Reflections on Regulation. Londres: Centre for Analysis of Risk and Regulation at the London School of Economics and Political Science, 2002.

BÖRKEY, P.; LÉVÊQUE, F. Voluntary Approaches for Environmental Protection in the European Union - a survey. European Environment, Volume 10, Issue 1, pages 35-54, OCDE, 2000.

CABUGUEIRA, M. Os acordos voluntários como instrumento de política ambiental. Porto: Editora Vida Econômica, 1999.

CANOTILHO, J. J. G. O direito ao ambiente como direito subjectivo. In: A tutela jurídica do meio ambiente: presente e futuro, Boletim da Faculdade de Direito da 
Universidade de Coimbra, Studia Juridica, no 81, 2005.

CARNEIRO, P. C. P. A Proteção dos Direitos Difusos Através do Compromisso de Ajustamento de Conduta Previsto na Lei que Disciplina A Ação Civil Pública. Tese aprovada no $9^{\circ}$ Congresso Nacional do Ministério Público, em Salvador, 1992.

Comunicado da Comissáo Europeia ao Parlamento Europeu e ao Conselho de Ministros sobre os Acordos Voluntários, a 27 de Novembro de 1996. Disponível em: $<$ http:// europa.eu/rapid/press-release PRES-97-204 pt.htm>, acesso em 30 de junho de 2016.

Convençáa Americana de Direitos Humanos. 1969. Disponível em: < http://www. cidh.oas.org/basicos/portugues/c.convencao_americana.htm>. Acesso em 21 set. 2017.

CONVERY, F.; LÉVÊQUE, F. Applying Voluntary Approaches - Some Insights from Research. CAVA International Policy Workshop on the Use of Voluntary Approaches, 2001.

CORDEIRO, A. Menezes de. Tutela do ambiente e direito civil. In: Direito do Ambiente. Lisboa: Instituto Nacional de Administração, 1993.

DIAS, J. E. de O. F. A reinvenção da autorizaçáo administrativa no direito do ambiente. Coimbra: Coimbra Editora, $1^{\text {a }}$ ed., 2014.

Fifth European Community environment programme: towards sustainability. Disponível em: <http://eur-lex.europa.eu/legal-content/PT/TXT/?uri=uriserv:128062>, acesso em 30 de junho de 2016.

GARCIA, M. da G F.P.D. O lugar do direito na protecçáo do ambiente. Coimbra: Ed. Almedina, 2007.

GOMES, Carla Amado; DIAS, José Eduardo Figueiredo. Notas reflexivas sobre sistemas de gestáo ambiental. In: Revista do Centro de Estudos de Direito do Ordenamento, do Urbanismo e do Ambiente. No 31, Ano XVI, 1.2013, p. 9-27.

GUNNINGHAM, N. Beyond compliance: next generation environmental regulation. Melbourne: Australian Institute of Criminology, 2002.

GUNNINGHAM, N.; SINCLAIR, D. Designing Smart Regulation. Oxford: Clarendon Press, 1998.

KIRKBY, M. B.-M. Os contratos de adaptaçáo ambiental: a concertação entre a administração pública e os particulares na aplicação de policia administrativa. Lisboa: Associação Académica da Faculdade de Direito de Lisboa, 2001.

LOPES, C. M. C. A legitimação participativa de uma decisão ambientalmente responsável. In: Revista do centro de estudos de direito do ordenamento, do urbanismo e do ambiente. No 29, Ano XV, 1.2012, p. 117-129.

MAÇÃS, M. F. Os acordos sectoriais como um instrumento da política ambiental. In: 
Revista do Centro de Estudos de Direito do Ordenamento, do Urbanismo e do Ambiente. Ano III, 1. 2000, p. 37-54.

MAZZILLI, H. N. Compromisso de ajustamento de conduta: evolução e fragilidades e atuação do Ministério Público. In: Revista de Direito Ambiental, vol. 41, p. 93, Jan/2006, DTR\2006/25. Disponível em: http://www.mazzilli.com.br/pages/artigos/ evolcac.pdf

MELLO, R. C. V. de. Acordos ambientais: um panorama luso-brasileiro. In Revista do Centro de Estudos de Direito do Ordenamento do Urbanismo e do Ambiente (CEDOUA), Coimbra, a. XIV, n. 27, p. 101-121, 2011.

MELLO, R. C. V. de. A insônia da princesa da fábula: acordos ambientais e governância. Dissertação de mestrado em Direito Administrativo na Faculdade de Direito da Universidade de Coimbra, Coimbra, 2009.

MILARÉ, E. Direito do ambiente. 10a edição revista, atualizada e ampliada. São Paulo: RT, 2015

NERY, A. L. de A. Compromisso de Ajustamento de Conduta: teoria e análise de casos práticos. São Paulo: Ed. RT, 2010.

OLIVEIRA, F.A.R. Competência. In: THEODORO Jr., H.; OLIVEIRA, F.A.R.; REZENDE, E.C.G.N. (eds.). Primeiras liçóes sobre o novo direito processual civil brasileiro: de acordo com o Novo Código de Processo Civil, Lei 13.105, de 16 de março de 2015. Rio de Janeiro: Forense, 2015, p. 64-81.

ORTIZ, I. y SOLANO, D. La Libre Competencia Económica y la Protección del Medio Ambiente: Una aproximación al estudio de los Acuerdos Voluntarios de Cumplimiento Ambiental. In: Revist@ E-Mercatoria, vol. 15, N 1, enero-junio, 2016.

PAIVA, T. M. D. de. O modelo de comportamento dos consumidores “verdes" portugueses: uma análise crítica. Tese de doutoramento em Marketing apresentada ao Instituto Superior das Ciências do Trabalho e da Empresa. Lisboa, 2003.

PRIEUR, M.. Droit de l'environnement. Paris: Dalloz, 2001.

RODRIGUES, G. de A. Princípios da celebração do compromisso de ajustamento de conduta em matéria ambiental. In: Revista do Centro de Estudos de Direito do Ordenamento, do Urbanismo e do Ambiente. No 13, ano VII, 1.2004, p. 67-88.

SANTOS, B. de S. O Direito e a comunidade. As transformações recentes da natureza do poder do Estado nos países capitalistas avançados. In: Revista Direito e Avesso, Brasilia, col. II, no 3, p.138-156, jan/jul. 1983.

Sexto programa de acçáo em matéria de ambiente. Disponivel em: <http://eur-lex.europa.eu/legal-content/PT/TXT/?uri=URISERV\%3Al28027>. Acesso em: 30 jun 2016.

Voluntary Environmental Agreements. Bureau Européen des Unions de Consom- 
mateurs, BEUC/X/060/2006. Disponível em: <http://ec.europa.eu/reducing_co2_emissions_from_cars/doc_contrib/beuc_voluntary_environmental_agreements_en.pdf $>$, acesso em 15 de mar. de 2016.

WOLF, B. Organized environmental crime: an analysis of corporate noncompliance with the law. Lewiston/Queenston/Lampeter: The Edwin Mellen Press, 2009. 